\title{
Metabolism of Catecholamines in Hyper- and Hypo-thyroid Patients
}

\author{
$\mathrm{By}$ \\ Nozomu Ishida

\begin{abstract}
From the Department of Internal Medicine, Tohoku University School
\end{abstract} \\ of Medicine, Sendai; Director: Prof. Dr. T. Torikai
}

(Received for publication, September 23, 1962)

\section{INTRODUCTION}

The role of catecholamines in patients with thyroidal dysfunction has long called much attention of many investigators. It is a well-known fact that the signs and symptoms of hyperthyroidism resemble those of pheochromocytoma, which are caused by large amounts of catecholamines secreted from the tumor. Palpitation, tachycardia, finger tremor, glycosuria, increased pulse pressure and anxiety are the usual signs of the former, and are all produced in healthy subjects by infusing adrenaline. Goetsch ${ }^{1)}$, Santesson ${ }^{2)}$ and Rosenblum ${ }^{3)}$ observed that the thyroid hormone exaggerates the cardiovascular effects of catecholamines. Brewster ${ }^{4}$ discussed that the signs of hyperthyroidism might be interpreted as a result of increased catecholamine activities caused by thyroxine.

If the activity of catecholamine is increased in hyperthyrodism, the following three mechanisms may be considered:

1) Higher responsiveness of the receptor to catecholamines.

2) Overproduction of catecholamines.

3) Delayed inactivation of catecholamines.

It has been ascertained by many authors that the response to injected adrenaline or noradrenaline is stronger in patients with hyperthyroidism than in normal controls, but the mechanism of this phenomenon has never been elucidated. Diller $^{5)}$ and Goldfien ${ }^{6}$ ) reported an overproduction of catechol hormones in this disease, but Euler ${ }^{7)}$ could not find this. As to the third possibility, Spinks and Burn $^{8}$, and Trendelenburg ${ }^{9}$ observed a decreased activity of monoamine oxidase, and D'Iorio ${ }^{10)} \mathrm{O}$-methyl transferase, in the liver homogenate from hyperthyroid rats; but Holtz ${ }^{11)}$ did not support these reports.

Recently, the metabolism of catecholamines has been clarified in details, and the determination of their metabolites was made possible. Using these new techniques of determination, the following studies were carried out in patients

石田望


with thyroid diseases to investigate the relation between thyroid dysfunction and catechol hormones:

1) Responsiveness to infused catecholamines.

2) Secretion of catecholamines.

3) Urinary excretion of their metabolites, metadrenaline, normetadrenaline and vanillylmandelic acid (VMA).

4) Behavior of the enzymes which inactivate catecholamines.

5) Metabolism of exogenous catecholamines.

The results will be described below.

\section{EXPERIMENTS AND RESULTS}

\section{1) Responsiveness to Infused Catecholamine}

Five patients with hyperthyrodism, 1 with hypothyrodism and, as control study, 7 healthy persons were infused with noradrenaline. The infusion was carried out according to Goldenberg ${ }^{12)} ; 5$ per cent glucose was infused into an antecubital vein of patients until their blood pressure and pulse rate became stabilized, then noradrenaline solution ( $d l$-noradrenaline hydrochloride, $1 \mathrm{mg}$. per $250 \mathrm{ml}$. of 5 per cent glucose) was substituted by means of three way stop

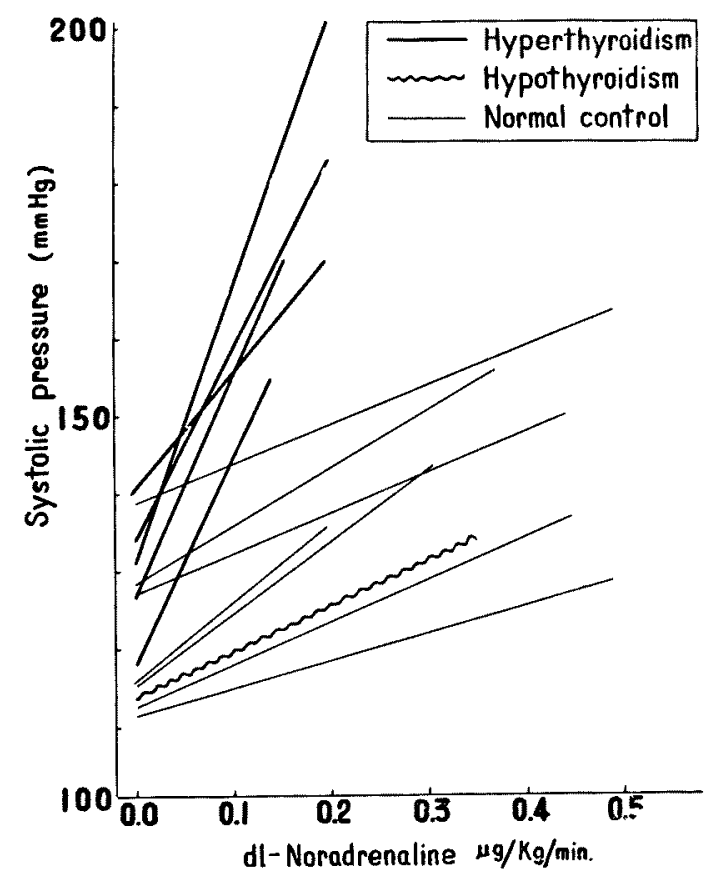

Fig. 1. Systolic blood pressure response to noradrenaline infusion. 
cock. The dose was gradually increased from 0.1 to $0.5 \mu \mathrm{g} . / \mathrm{Kg} / \mathrm{min}$. Blood pressure and pulse rate were measured every minute throughout the infusion.

Fig. 1 illustrates the results. In 7 control subjects, the response in blood pressure was not so marked. On the other hand, hyperthyroid patients responded with abrupt blood pressure elevation even to such low doses of $0.1-0.2 \mu \mathrm{g} . / \mathrm{Kg}$. $/$ min. One patient with hypothyroidism showed comparable sensitivity to normal control. In conclusion, the responsiveness to infused noradrenaline was greater in hyper- and normal in hypo-thyroid patients.

\section{2) Secretion and Excretion of Catecholamines in Thyroid Patients}

Urinary free catecholamines were determined in 25 hyper-, 2 hypo- and 20 eu-thyroid subjects using the trihydroxyindole method of Euler and Floding, modified by Yoshinaga. ${ }^{13)}$ They were asked to void at 2 p.m., and to lie quietly in bed for two hours, then their urines were collected at 4 p.m., thus the postural influence on the catecholamine excretion was excluded. Basal metabolic rate (BMR), protein bound iodine (PBI), 24 hour uptake of $\mathrm{I}^{131}$ ( $\mathrm{I}^{131}$ uptake), pulse rate

TABLE I. Urinary Exeretion of Catecholamines and Thyroid Functions in Patients with Hyperthyroidism. 1, A: Adrenaline $(\mu \mathrm{g} . / \mathrm{h})$ 2, NA: Noradrenaline $(\mu \mathrm{g} . / \mathrm{h}) \quad 3, \mathrm{~A} / \mathrm{CA}: \mathrm{A} / \mathrm{A}+\mathrm{NA} \quad 4, \% \quad 5, \%$

in $24 \mathrm{hrs} .6, \mu \mathrm{g} . / \mathrm{dl}$.

\begin{tabular}{|c|c|c|c|c|c|c|c|c|c|c|c|}
\hline Patient & Sex & Age & $A^{1}$ & $\mathrm{NA}^{2}$ & $\mathrm{~A} / \mathrm{CA}^{3}$ & $\begin{array}{c}\text { Blood } \\
\text { pressure }\end{array}$ & $\begin{array}{c}\text { Pulse } \\
\text { pressure }\end{array}$ & $\begin{array}{c}\text { Pulse } \\
\text { rate }\end{array}$ & BMR $^{4}$ & $\begin{array}{c}\mathrm{I}^{131} \\
\text { uptake }^{5}\end{array}$ & $\mathrm{PBI}^{6}$ \\
\hline Т.O. & M & 55 & 0.59 & 2.06 & 22.3 & $140 / 82$ & 58 & 57 & 26 & 42.3 & 9.1 \\
\hline K.S. & $\mathrm{F}$ & 19 & 0.12 & 2.09 & 5.4 & $112 / 74$ & 38 & 90 & 20.5 & 67.5 & 8.2 \\
\hline N.K. & $\mathrm{F}$ & 19 & 0.31 & 1.29 & 19.4 & $130 / 58$ & 72 & 102 & 27.5 & 68 & 12.8 \\
\hline S.W. & $\mathrm{F}$ & 57 & 0.24 & 1.04 & 18.7 & $120 / 62$ & 70 & 83 & 64 & 67.5 & 16.1 \\
\hline T.S. & $\mathrm{F}$ & 20 & 0.40 & 0.98 & 29.0 & $142 / 54$ & 88 & 99 & 59.5 & 64.9 & 10.5 \\
\hline T.S. & M & 54 & 0.54 & 1.80 & 23.1 & $140 / 68$ & 72 & 80 & 44 & 67.9 & 8.9 \\
\hline H.A. & $\mathrm{F}$ & 50 & 0.30 & 0.98 & 23.4 & $128 / 76$ & 52 & 69 & 17.7 & 53.1 & 3.5 \\
\hline K.K. & $\mathrm{F}$ & 26 & 0.42 & 1.03 & 29.0 & $124 / 58$ & 66 & 120 & 74 & 69.5 & 10.1 \\
\hline Y.Y. & $\mathrm{F}$ & 28 & 0.25 & 0.94 & 21.1 & $116 / 68$ & 48 & 87 & 32.5 & 60.6 & 8.4 \\
\hline T.O. & $F$ & 36 & 1.07 & 2.75 & 28.1 & $118 / 72$ & 46 & 72 & 36.5 & 65.2 & 10.5 \\
\hline E.M. & $\mathrm{F}$ & 39 & 0.31 & 1. 19 & 20.6 & $124 / 58$ & 66 & 102 & 60 & 70.2 & 14.1 \\
\hline M.Y. & $F$ & 36 & 0.09 & 0.74 & 10.8 & $116 / 62$ & 54 & 78 & 24 & 53.4 & 9.8 \\
\hline K.S. & $\mathrm{E}$ & 40 & 0.27 & 1.71 & 13.6 & $124 / 62$ & 62 & 90 & 53.5 & 35.6 & 8.8 \\
\hline T.A. & $\mathrm{F}$ & 57 & 0.45 & 1.55 & 22.5 & $130 / 82$ & 48 & 80 & 35.5 & 74.4 & 11.9 \\
\hline М.H. & M & 44 & 0.26 & 2.22 & 10.5 & $122 / 62$ & 60 & 72 & 54 & 47.1 & 15. 4 \\
\hline Y.S. & $\mathrm{F}$ & 27 & 0.60 & 1.02 & 37.0 & $140 / 70$ & 70 & 74 & 62 & 61.3 & 11.0 \\
\hline S.U. & M & 34 & 0.38 & 1.69 & 18.4 & $138 / 64$ & 74 & 84 & 25.5 & 71.3 & 8.1 \\
\hline H.S. & $\mathrm{F}$ & 55 & 0.55 & 1.89 & 22.5 & $144 / 60$ & 84 & 120 & 70.5 & 61.3 & 9.8 \\
\hline Y.U. & 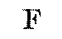 & 46 & 0.52 & $2.9 b$ & 15.0 & $116 / 76$ & 40 & 114 & 48.5 & 67.5 & 9.1 \\
\hline М.O. & M & 14 & 0.11 & 1.56 & 6.7 & $140 / 72$ & 68 & 114 & 34.5 & 14.0 & 8.9 \\
\hline Y.U. & M & 30 & 0.08 & 1.64 & 4.7 & $120 / 56$ & 64 & 96 & 35 & 50.0 & 19.5 \\
\hline F.K. & F & 39 & 0.37 & 0.65 & 36.2 & $116 / 50$ & 66 & 78 & 52.3 & 75.8 & 10. 5 \\
\hline M.S. & F & 48 & 0.54 & 1. 15 & 32.0 & $114 / 62$ & 52 & 80 & 32.0 & 50.6 & 10.5 \\
\hline C.T. & $F$ & 44 & 0.23 & 0.68 & 25.3 & $116 / 58$ & 58 & 78 & 38.5 & 80.2 & 7. 2 \\
\hline F.S. & $\mathrm{F}$ & 35 & 0.31 & 1. 68 & 15.6 & $130 / 72$ & 58 & 120 & 28 & 50.6 & 9.8 \\
\hline
\end{tabular}


TABLE II. Urinary Excretion of Catecholamines and Thyroid Function in Patients with Hypothyroidism

\begin{tabular}{|c|c|c|c|c|c|c|c|c|c|c|c|}
\hline Patient & Sex & Age & A & NA & $\mathrm{A} / \mathrm{CA}$ & $\begin{array}{c}\text { Blood } \\
\text { pressure }\end{array}$ & $\begin{array}{c}\text { Pulse } \\
\text { pressure }\end{array}$ & $\begin{array}{l}\text { Pulse } \\
\text { rate }\end{array}$ & BMR & $\begin{array}{c}\mathbf{I}^{\mathbf{1 3 1}} \\
\text { uptake }\end{array}$ & PBI \\
\hline T.S. & M & 45 & 0.23 & 1.88 & 10.8 & $116 / 60$ & 56 & 84 & 12.3 & 3.0 & 1.9 \\
\hline T.A. & M & 48 & 0.46 & 2.35 & 16.4 & $136 / 72$ & 64 & 60 & 9.0 & 0.0 & 2.4 \\
\hline
\end{tabular}

TABLE III. Urinary Excretion of Adrenaline and Noradrenaline $(\mu \mathrm{g} . / \mathrm{h}$, at Rest)

\begin{tabular}{l|c|c|c}
\cline { 3 - 4 } & Case & Adrenaline & Noradrenaline \\
\hline Normal Control & 20 & $0.404 \pm 0.048$ & $1.598 \pm 0.129$ \\
Hyperthyroidism & 25 & $0.371 \pm 0.043$ & $1.490 \pm 0.122$ \\
Hypothyroidism & 2 & $0.345 \pm 0.033$ & $2.115 \pm 0.230$
\end{tabular}

and pulse pressure were examined as parameters of thyroid function.

The results are given in Table; I-III. Control subjects excreted $0.404 \pm$ $0.048 \mu \mathrm{g} . / \mathrm{h}$. of adrenaline and $1.598 \pm 0.129 \mu \mathrm{g} . / \mathrm{h}$. of noradrenaline in their urine, these figures agreed well with that reported by Euler. ${ }^{14)}$ In patients with hyperthyroidism, $0.371 \pm 0.043 \mu \mathrm{g}$. of adrenaline and $1.490 \pm 0.122 \mu \mathrm{g}$. of noradrenaline were found in their hourly urines, the values did not differ significantly from that of controls. Two hypothyroid patients excreted $0.345 \pm 0.033 \mu \mathrm{g} . / \mathrm{h}$. and $2.115 \pm 0.230 \mu \mathrm{g} . / \mathrm{h}$. respectively.

The correlation of adrenaline or of noradrenaline with thyroid functions was tested, but any positive or negative correlation was not proved statistically. The ratio of adrenaline/catecholamines (adrenaline+noradrenaline) did not correlate with PBI nor with $\mathrm{I}^{131}$ uptake.

From these results, it may be concluded that the endogenous production of catecholamines is not changed in thyroid diseases.

\section{3) Excretion of Catecholamines and Their Metabolites in 24 Hour Urine}

Urinary metadrenaline and normetadrenaline were determined by the method of Yoshinaga et al. ${ }^{15)}$, and VMA by Sato's method. ${ }^{16)}$ The results are shown in Table IV, in which no difference is noted between thyroid patients and normal controls in their daily excretion of catecholamines and metabolites.

TABLE IV. Urinary Excretion of Adrenaline (A), Noradrenaline (NA), Metadrenaline (MA), Normetadrenaline (NMA) and Vanillylmandelic Acid (VMA) ( $\mu$ g. $/ 24$ h.).

\begin{tabular}{l|r|c|c|c|c|c}
\hline & Case & A & NA & MA & NMA & $\begin{array}{c}\text { VMA } \\
\text { (mg./24h.) }\end{array}$ \\
\hline Normal Control & 20 & $5.34 \pm 0.70$ & $20.19 \pm 2.24$ & $139.32 \pm 18.73$ & $119.94 \pm 11.04$ & $3.51 \pm 0.17$ \\
Hyperthyroidism & 14 & $5.82 \pm 1.42$ & $20.74 \pm 2.24$ & $132.24 \pm 20.63$ & $135.50 \pm 21.21$ & $3.33 \pm 0.33$ \\
Hypothyroidism & 2 & $4.05 \pm 0.07$ & $32.25 \pm 8.80$ & $98.00 \pm 4.95$ & $139.00 \pm 14.85$ & $3.63 \pm 0.35$
\end{tabular}


The above described conclusion that the endogenous production of catecholamines is not changed in thyroid diseases was supported by this study on the 24 hour excretion of these hormones and their metabolites.

\section{4) The Ratio of Catecholamines/Methoxy Catecholamines/VMA}

The main metabolic pathway of catecholamines has recently been clarified as illustrated in Fig. 2. If the activities of the catecholamine inactivating enzymes,

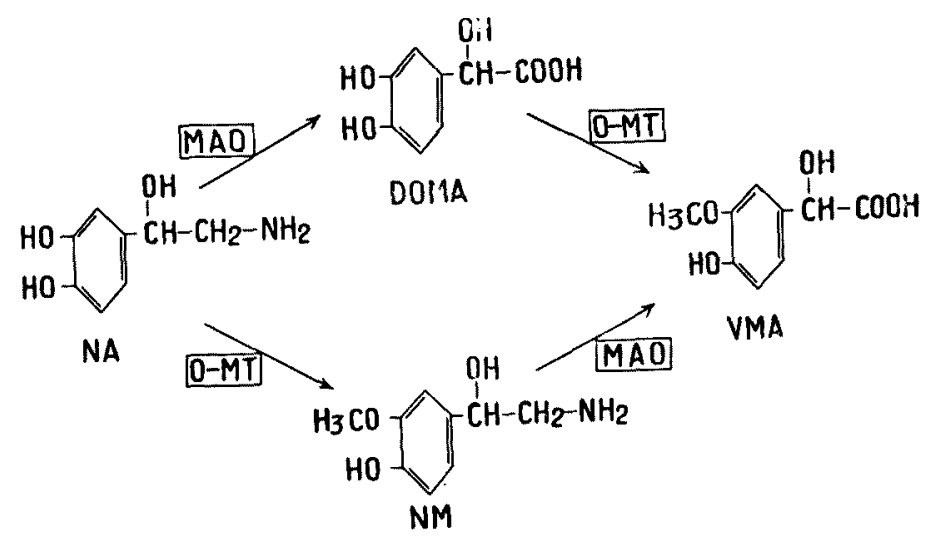

Fig. 2. Main metabolic pathway of noradrenaline.

monoamine oxidase and catechol $\mathrm{O}$-methyl transferase, are weakened in thyroid patients, the metabolism of the hormones should be stopped or delayed at certain steps of the pathway; decrease in VMA and increase in methoxy catecholamines and catecholamines should result from a depressed activity in monoamine oxidase, whereas a decrease in both VMA and methoxy catecholamines and increase in catecholamines from weakened activity in O-methyl transferase; thus a marked change in the ratio of catecholamines/methoxy catecholamines/VMA should be observed if the enzyme activities are altered in thyroid patients.

A potent monoamine oxidase inhibitor, JB-516, was administered orally to 3 healthy persons, $12 \mathrm{mg}$. a day for 1 week. Catecholamines and their metabolites in urine before, during and after the medication with the drug in one of three experiments are shown in Fig. 3. As expected, inhibition of monoamine oxidase blocked the transformation of methoxy catecholamines to VMA, resulting in an increase in the excretion of metadrenaline and normetadrenaline and decrease in VMA. The ratio catecholamines/methoxy catecholamines/VMA changed from the initial $1 / 11 / 120$ to $1 / 16 / 44$.

The ratio was calculated in thyroid patients and control subjects (Fig. 4 and Table V). No difference was noted between the two groups. The individual values 


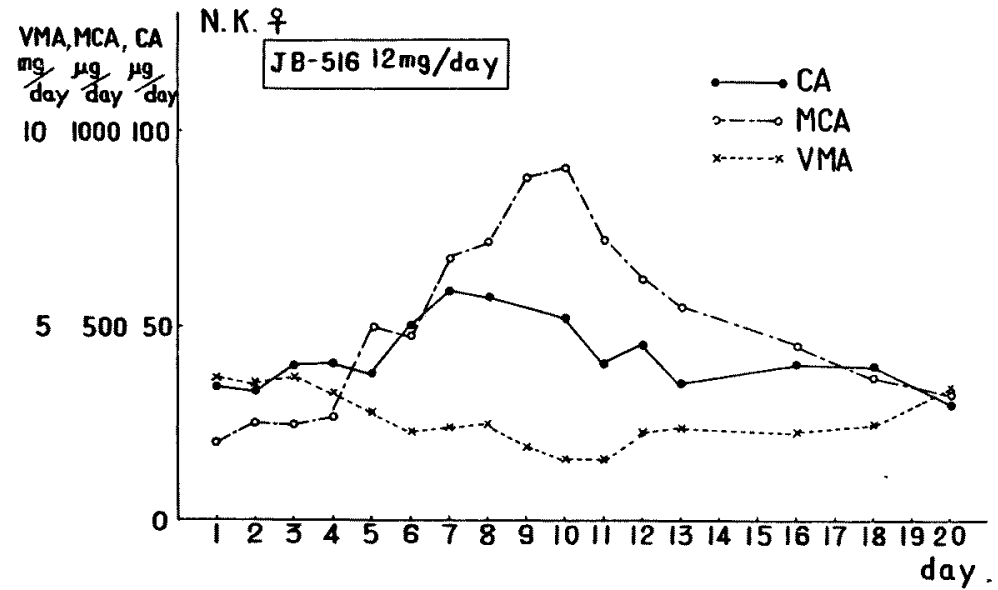

Fig. 3. Effect of JB-516 administration on the urinary excretion of catecholamine (CA), methoxy catecholamine (MCA) and vanillylmandelic acid (VMA).

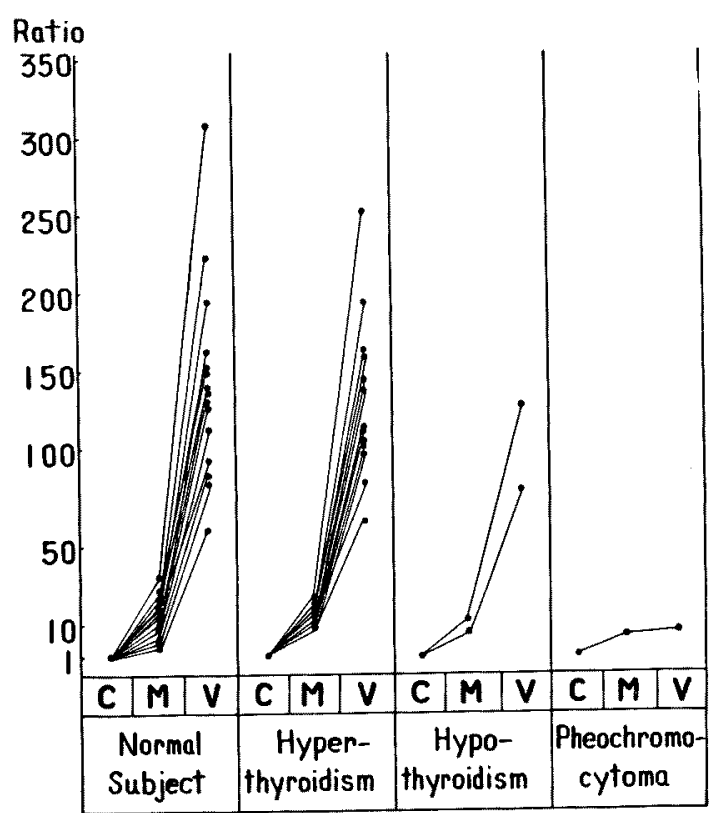

Fig. 4. Excretion ratio of catecholamine (C): methoxy catecholamine (M): vanillylmandelic acid (V) in 24 hour urine.

TABLE V. Urinary Excretion Ratio of Catecholamines (C), Methoxycatecholamines (M) and Vanillylmandelic Acid. (V).

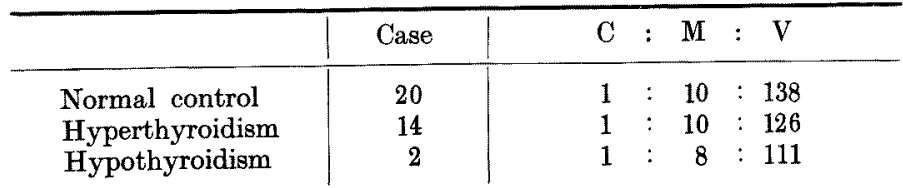


of catecholamines, methoxy catecholamines and VMA were also within normal range in thyroid patients. These results might be interpreted as indicating no enzymatical abnormality in both monoamine oxidase and O-methyl transferase in thyroid patients.

\section{5) Metabolism of Exogenous Catecholamines}

Four healthy, 4 hyper- and 2 hypo-thyroid subjects were infused with noradrenaline, and the metabolism of the exogenous noradrenaline was studies by measuring catecholamines, methoxy catecholamines and VMA in 24 hour urines of these subjects. They were asked to void at 8 a.m., to lie quietly in bed till $10 a, m$. when the urine was collected as pre-infusion control. $d l$-noradrenaline bydrochloride dissolved in 5 per cent glucose was infused intravenously in doses ranging $2-5 \mathrm{mg}$. in the following two hours. $5-25 \mathrm{mg}$. of regitine was previously added to the infusion solution in order to prevent the toxic effects of noradrenaline. During the infusion, blood pressure and pulse rate of the subjects were frequently checked, and much care was taken against untoward side reactions which were in fact never encountered. Immediately after infusion (12 a. m.), and at 2, 4, 6,

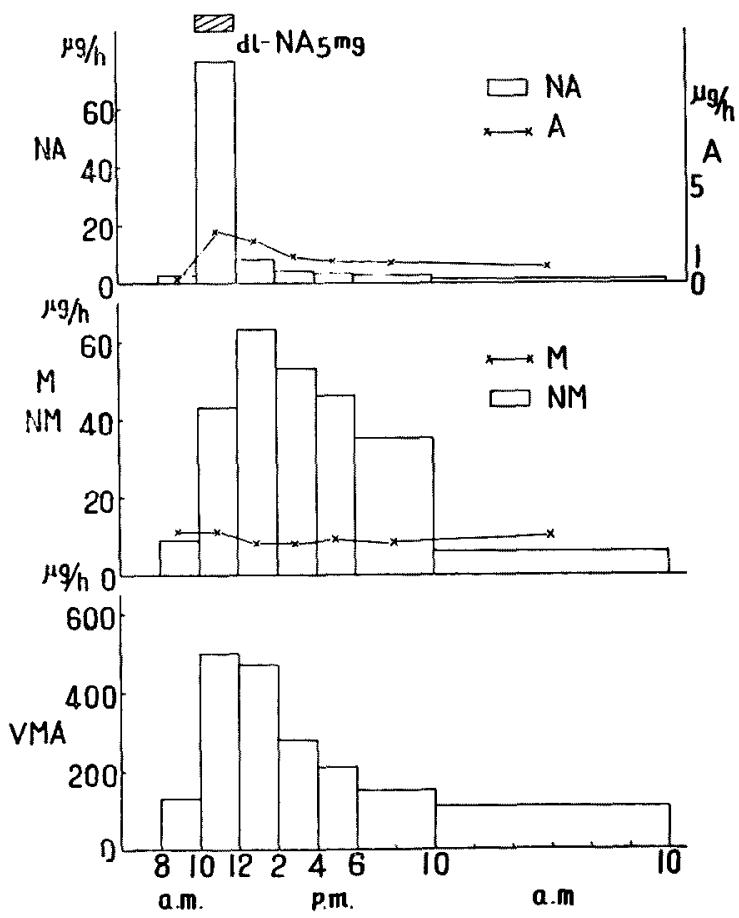

Fig. 5. Urinary excretion pattern of catecholamines and their metabolites after noradrenaline infusion (normal subject). 
$10 \mathrm{p} . \mathrm{m}$. and finally at $10 \mathrm{a} . \mathrm{m}$. next morning, urine was collected. Each urine specimen was analysed for its contents of catecholamines, methoxy catecholamines and VMA.

Fig. 5 illustrates the pattern of excretion of catecholamines and their metabolites in healthy control subjects. Excretion of noradrenaline was largest during the infusion, rapidly decreased thereafter and returned to control level after 2 hours. Contrary to noradrenaline, excessive excretion of its metabolites, normetadrenaline and VMA, lasted for several hours, returning gradually to control level after 10 hours or more, their peak was often found in the second urine specimen collected 2 hours after the infusion. The excretion pattern of both catecholamines and their metabolites in thyroid patients did not differ from that in euthyroid controls.

The recovery of infused noradrenaline in urine collected for 24 hours following the infusion was 2.9-3.3 per cent in control subjects, 2.4-4.0 in hyperthyroid patients and 2.1-2.6 in hypothyroid subjects (Table VI). These figures in the recovery agreed well with the report of Euler. ${ }^{17)}$

In three cases out of four hyperthyroid patients, the ratio adrenaline/ noradrenaline in 24 hour urine was $22.7,12.9$ and 36.0 , markedly higher ratio than that in eu- or hypo-thyroid subjects. The ratio metadrenaline/normetadrenaline was also higher in these patients, namely $67.6,62.5$ and 127.6 respectively.

The ratio catecholamines/methoxy catecholamines/VMA was calculated in each individual urine specimen collected during and after the infusion up to 24 hours. This ratio was not different in every comparable urine samples between thyroid patients and normal controls with a minor exception that the value of metadrenaline during the infusion was slightly increased in hyperthyroid patients, but it was normal in 24 hour urine.

From these results in the study on the metabolism of exogenous noradrenaline, it may be concluded that the catecholamine inactivators, monoamine oxidase and $\mathrm{O}$-methyl transferase, are normally functioning in thyroid patients.

\section{DISCUSSION}

It has been known that the cardiovascular response to injected catecholamines is excessive in patients with hyperthyroidism. ${ }^{1-2}$ This hypersensitivity was confirmed by the present study. Recently, Schneckloth et al. ${ }^{18)}$ observed that the pressor response caused by the injection of adrenaline was increased in parallel with the severity of the thyrotoxicosis, and Murray et al. ${ }^{19)}$ reported that the response to adrenaline in thyroid patients was of diagnostic value as well as the basal metabolic rate, protein bound iodine or $\mathrm{I}^{131}$ uptake.

However, the mechanism of this hypersensitivity is not yet known, though many hypotheses have been proposed for. One of these hypotheses 
TABLE VI. Urinary Excretion of Catecholamines and Their Metabolites during (5) Methoxy $\mathrm{CA}=\mathrm{M}+\mathrm{NM}$,

Control Subjects

\begin{tabular}{l|r|c|c|c|c|c|c|c|}
\hline & $\mathrm{A}^{(1)}$ & $\mathrm{NA}^{(1)}$ & $\mathrm{CA}^{(2)}$ & $\mathrm{A} / \mathrm{NA}^{(3)}$ & $\begin{array}{c}\text { Recovery } \\
\text { of } \mathrm{NA}\end{array}$ & $\mathrm{M}^{(1)}$ & $\mathrm{NM}^{(1)}$ & $\begin{array}{c}\text { Methoxy } \\
\mathrm{CA}\end{array}$ \\
\hline 1. S.G. & 17.69 & 206.40 & 224.09 & 8.6 & 3.0 & 237.9 & 527.7 & 765.6 \\
2. H.S. & 11.74 & 176.56 & 188.30 & 6.7 & 3.3 & 161.7 & 451.9 & 613.6 \\
3. K.S. & 11.39 & 193.99 & 205.38 & 5.9 & 2.9 & 155.0 & 566.6 & 721.6 \\
4. Y.G. & 5.90 & 133.14 & 139.04 & 4.4 & 2.9 & 103.2 & 331.2 & 434.4 \\
\hline
\end{tabular}

Hyperthyroid Patients

\begin{tabular}{l|r|r|r|r|r|r|r|r} 
1. S.T. & 28.26 & 124.39 & 152.65 & 22.7 & 2.6 & 264.6 & 390.0 & 654.6 \\
2. Y.U. & 18.12 & 140.61 & 158.73 & 12.9 & 2.4 & 275.1 & 420.0 & 695.1 \\
3. M.S. & 18.84 & 187.81 & 201.65 & 7.4 & 4.0 & 182.0 & 637.3 & 819.3 \\
4. M.I. & 20.53 & 57.28 & 77.81 & 36.0 & 2.4 & $\mathbf{2 9 7 . 4}$ & 232.9 & 530.3
\end{tabular}

Hypothyroid Patients

\begin{tabular}{l|r|r|r|r|l|l|l|l} 
1. T.S. & 11.17 & 142.39 & 153.56 & 7.8 & 2.1 & 152.5 & 667.1 & 819.6 \\
2. N.T. & 9.17 & 153.95 & 163.12 & 5.9 & 2.6 & 106.1 & 357.6 & 464.1
\end{tabular}

assumes a decreased activity of monoamine oxidase. If the enzyme activity be lowered under the influence of thyroid hormone, inactivation of catecholamines should delay, causing hypersensitivity to catecholamines in hyperthyroid patients. Spink $\mathrm{s}^{20}$ ) observed lowered monoamine oxidase activity in the wall of aorta in rabbits administered with thyroxin. Burn ${ }^{21}$ supported the hypothesis with many experiments.

The second possibility accounting for the hyperesensitivity had to be considered in relation to the receptor of catecholamines. Burn has recently announced his concept that the response of organs to adrenaline or noradrenaline is increased with the decrease in the content of catecholamines in that organ. $\mathrm{He}$ deduced this conclusion from the observation that the spiral strips of rabbit aorta, in which the tissue catecholamines was previously depleted by reserpine, responded more vigorously than untreated controls. Therefore, the increased sensitivity in hyperthyroid patients is easily explainable if the catecholamine content in the cardiovascular system is lowered in these patients, but the investigations of this kind have never been performed in human beings.

As to the urinary excretion of catecholamines in thyroid patients, Diller et $a l^{5)}$ reported using biological assay technique that the excretion of adrenaline in hyperthyroidism is increased in parallel with its severity. Goldfien et al. ${ }^{6)}$ found with the ethylenediamine condensation method an increased plasma level of adrenaline in patients with hyperthyroidism. On the other hand, Euler ${ }^{7)}$ stated 
and after Noradrenaline Infusion.

(6) $\mathrm{mg} . /$ day, (7) $\mathrm{R}=$ Regitine.

(1) $\mu \mathrm{g} . /$ day, (2) $\mathrm{CA}=\mathrm{A}+\mathrm{NA}, \quad$ (3), (4) $\%$

\begin{tabular}{|c|c|c|c|c|c|c|c|c|c|c|c|}
\hline \multirow{2}{*}{$\begin{array}{c}\mathrm{M} / \mathrm{NM}^{(3)} \\
45.2\end{array}$} & \multirow{2}{*}{$\frac{\mathrm{VMA}^{(6)}}{5001}$} & \multicolumn{4}{|c|}{$\begin{array}{l}\text { C : } \mathrm{M}: \text { V } \\
\text { during Infusion }\end{array}$} & \multicolumn{3}{|c|}{$\begin{array}{c}\mathrm{C}: \mathrm{M}: \mathrm{V} \\
\text { in } 24 \mathrm{hr} \text { Urine after } \\
\text { Infusion }\end{array}$} & \multicolumn{3}{|c|}{$\begin{array}{l}\text { Dose of Infusion } \\
\text { (mg.) }\end{array}$} \\
\hline & & 1 & : & 0.7 & 6.3 & 1 & 3 & 23 & $\mathrm{NA}: 5$, & $\mathrm{R}$ & 7) $: 25$ \\
\hline 35.7 & 54.68 & 1 & : & 0.5 & 5.9 & 1 & : & 29 & " & & $" \prime$ \\
\hline 27.4 & 9236 & 1 & : & 0.2 & $: 6.0$ & 1 & 4 & 45 & "I & & $" \prime$ \\
\hline 31.0 & 4929 & 1 & $:$ & 0.6 & $: 11: 1$ & 1 & $:$ & 36 & $\mathrm{NA} ; 4$, & $\mathbf{R}$ & $; 20$ \\
\hline
\end{tabular}

\begin{tabular}{r|l|lllll|llllll|l}
\hline 67.6 & 6502 & 1 & $:$ & 0.9 & $:$ & 6.8 & 1 & $:$ & 4 & $:$ & 49 & $\mathrm{NA} ; 4, \mathrm{R} ; 20$ \\
65.5 & 6929 & 1 & $:$ & 0.4 & $:$ & 5.2 & 1 & $:$ & 4 & $:$ & 44 & $\mathrm{NA} ; 5, \mathrm{R} ; 20$ \\
28.5 & 3826 & 1 & $:$ & 1.2 & $:$ & 6.7 & 1 & $:$ & 4 & $:$ & 19 & $\mathrm{NA} ; 4, \mathrm{R} ; 20$ \\
127.6 & 6628 & 1 & $:$ & 1.0 & $:$ & 3.6 & 1 & $:$ & 7 & $:$ & 85 & $\mathrm{NA} ; 2, \mathrm{R} ; 5$ \\
& & & & & & & \\
\end{tabular}

that any definite relationship between catecholamine excretion and thyroid disease was not found in spite of repeated examinations. Papers concerning urinary excretion of the metabolites of catecholamines in thyroid patients have never been published in the literature. In the present study, any distinct change in the urinary excretion of catecholamines and their metabolites was not observed in thyroid patients.

Nowadays, it is generally accepted that the main metabolic pathway of catecholamines is catecholamine $\rightarrow$ methoxy catecholamine (or dihydroxy-mandelic acid) $\rightarrow$ VMA. Therefore, if the endogenous production of catecholamines is increased in a certain disease, patients suffering from that disease should excrete increased amounts of catecholamines, methoxy catecholamines and VMA. But the present study showed no distinct difference in the excretion of these substances between hyper- and eu-thyroid subjects. This may be interpreted as indicating that the endogenous production of catecholamines is not altered in hyperthyroid patients.

My collaborators Yoshinaga et $a{ }^{23)}$ reported that the patients with pheochromocytoma showed decreased sensitivity to noradrenaline infusion. It may be unlikely from their observation that hypersensitivity and overproduction coexist in Graves' disease.

In contrast to Diller's report, any significant correlation was not obtained in the present study between urinary excretion of catecholamines and thyroid 
functions such as basal metabolic rate, protein bound iodine and uptake of $I^{131}$. This result is supported by the study of Mowbray et al. ${ }^{24)}$ who observed no change in $\mathrm{I}^{131}$ uptake and protein bound iodine in patients infused with adrenaline and/or noradrenaline.

Though the number of hypothyroid patients studied was so few that any conclusions could not be derived from this investigation, no definite change in urinary catecholamines, methoxy catecholamines, and VMA was noted and no correlation between catecholamine output and thyroid functions was observed in hypothyroid as in hyperthyroid patients.

Spinks and Burn ${ }^{8)}$, Trendelenburg ${ }^{9)}$, Zile et al. $^{25)}$ observed a decreased monoamine oxidase activity in the homogenate of liver in rats or rabbits administered pulverized thyroid gland. But Holtz et al.11) did not find any enzymatical changes under similar experimental conditions. Spinks and Burn ${ }^{8}$ ) further reported an increased monoamine oxidase activity in the liver homogenate of thyroidectomized rats. D'Iorio et al. ${ }^{10}$ ) found a weakened activity of $\mathrm{O}$-methyl transferase in liver of rats treated with thyroxin.

If these catecholamine inactivating enzymes are altered in their activities in thyroid patients, the metabolism of catecholamines (catecholamines $\rightarrow$ methoxy catecholamines $\rightarrow$ VMA) should be modified in them. In my experiments, marked change in the ratio of urinary catecholamines/methoxy catecholamines/VMA from the normal $1 / 11 / 120$ to $1 / 16 / 44$ was observed in healthy subjects recieving a monoamine oxidase inhibitor, JB-516, in a dose of $12 \mathrm{mg}$. per day. This change speaks for a distinct block in the transformation of methoxy catecholamines to VMA, resulting in an increased excretion of the former and a decrease of the latter.

If the activity of monoamine oxidase is weakened in hyperthyroid patients, as is the case in experimental hyperthyroid animals reported by Spinks and Burn, the excretion of methoxy catecholamines should increase, VMA should decrease and the ratio methoxy catecholamines/VMA should increase markedly as seen in the experiment on monoamine oxidase inhibitor in healthy subjects.

Again, if the O-methyl transferase is suppressed in the patients, as reported in the liver of rats administered thyroxin by D'Iorio $e t$ al., urinary catecholamines should increase, methoxy catecholamines and VMA should decrease, and the ratio catecholamines/methoxy catecholamines/VMA should deviate from the normal. But in fact the metabolites or their ratio were within normal range in hyperthyroid patients as described above.

The enzyme activities may also be studied by investigating the fate of parenterally administered catecholamines. liesnick et al. ${ }^{26)}$ reported that the rats treated with iproniazid excreted greater metadrenaline and smaller VMA in urine than control animals without treatment after the injection of $\mathrm{C}^{14}$ labelled adrenaline. If the activities of the enzymes are abnormal in thyroid patients, infusion of catecholamines into the patients should result in an altered catecholam- 
ines/methoxy catecholamines/VMA ratio in their urine compared with healthy subjects. But in the present study, no difference was observed in that ratio in 2-24 hour urine specimens after the infusion of noradrenaline between the two groups.

From these results, it may be concluded that monoamine oxidase and 0 methyl transferase are normally functioning in thyroid patients. But the possibility, offered by Burn in the explanation of increased sensitivity to catecholamines in hyperthyroid animals, that the enzyme activity is altered only in the vascular wall leaving the other tissues intact, is not investigated in this study.

Euler ${ }^{17)}$ was the first in performing the study on the urinary excretion of catecholamine after its infusion. Recently this sort of investigation has been widely carried out using radioactive catecholamines. However, infusion experiment in thyroid patients has never been reported in the literature.

In the present study, 2.6-3.3 per cent of infused noradrenaline was recovered in urine samples voided immediately after the infusion in healthy subjects, the figures were in good agreement with those reported by Euler. ${ }^{17}$ ) But since the urine collection is apt to be incomplete because of its partial residue in the bladder, the excretion figures should be studied in urine samples voided for hours after the infusion. The amounts of excreted noradrenaline in 24 hour postinfusion urine attained to 2.9-3.3 per cent of infused doses in both thyroid patients and control subjects.

The excretion of noradrenaline was largest during infusion, and returned rapidly to pre-infusion level in 2 hours, while the metabolites were excreted in elevated quantities for several hours after the infusion, indicating that the level of circulating noradrenaline, but not of its metabolites, decreased rapidly to normal after the cessation of its administration. In experiments of noradrenaline infusion into healthy persons, Cohen ${ }^{27}$ ) measured blood level of catecholamines with his trihydroxy indole method and found a very short half-life of 1-2 min. of noradrenaline in general circulation.

It is well known that circulating catecholamines are taken up in tissues. ${ }^{28}$ ) Infused catecholamines may be taken up as active forms in various tissues where they are gradually metabolized to be released again in the circulation as catabolites, or may be immediately subjected to metabolism and the metabolites were stored in tissues from which they are slowly released back to the circulation. The pattern of the excretion of noradrenaline and its metabolites were not different between hyper- and eu-thyroid subjects in this study. But this result speaks nothing on the problem of the uptake of catecholamines by tissues.

The ratios adrenaline/catecholamines (adrenaline+noradrenaline) and metadrenaline/methoxy catecholamines (metadrenaline + normetadrenaline) cal- 
culated in post-infusion urine were remarkably higher in hyperthyroid group than in controls. This difference may be explained by the following tbree possibilities:

1) Hyperthyroid patients respond to infused noradrenaline more vigorously because of their higher sensitivity to catecholamines than normal controls, the severity of the reaction causes augmented liberation of adrenaline from the adrenal medulla.

2) N-methylation of noradrenaline to adrenaline occurs in hyperthyroid patients.

3) N-methylation of normetadrenaline to metadrenaline occurs in hyperthyroid patients.

Euler ${ }^{17}$ has disproved the possibility 2). Concerning the possibility 3), Axerlod ${ }^{29)}$ found under special experimental condition in vitro an enzyme which demethylate from metadrenaline to normetadrenaline, but could find no pathway from metadrenaline to normetadrenaline or from normetadrenaline to metadrenaline in vivo. Therefore, the possibility 1) may be considered most probable.

From the early stages of investigation in thyroid diseases, it has been well known that thyroid hormone causes increased sensitivity to injected catecholamines, but the mechanism involved in this hypersensitivity has never been elucidated. The problem was studied in this report by investigating the sensitivity to infused noradrenaline, excretion of catecholamines and their metabolites, but no clue was found. Another way to attack the problem may be left in the study on the uptake of catecholamines by tissues.

Hertting et al..$^{30}$ ) and De Schaepdryver et al.31) studied the uptake of exogenously administered radioactive catecholamines. Goodall ${ }^{32}$ ) and Leduc et al. ${ }^{33)}$ investigated this problem in hyperthyroid patients. But no conclusion has been attained up to date, leaving the problem to be elucidated in the future.

\section{CONCLUSION}

1) In patients with hyperthyroidism, the sensitivity to infused noradrenaline was distinctly increased. One hypothyroid patient reacted normally to the infusion.

2) Both hyper- and hypothyroid patients excreted comparable amounts of adrenaline, noradrenaline, metadrenaline, normetadrenaline and vanillylmandelic acid (VMA) to normal controls. It may be concluded that the endogenous production of catecholamines is normal in thyroid patients.

3) Basal metabolic rate, protein bound iodine, uptake of $I^{131}$, systolic and diastolic blood pressure, pulse pressure, and pulse rate were all in no correlation with either urinary adrenaline or noradrenaline in thyroid patients.

4) The ratio urinary catecholamines/methoxy catecholamines/VMA was within normal range in thyroid patients. The ratio calculated in the urine 
obtained after noradrenaline infusion was not significantly different in thyroid patients from that in healthy controls under similar experimental condition. This may be interpreted as indicating no enzymatical abnormality in monoamine oxidase and catechol $\mathbf{0}$-methyl transferase.

5) Recovery of infused noradrenaline in urine excreted for 24 hours after its infusion was 2.9-3.3 per cent in patients with hyperthyroidism as in normal controls.

6) In the experiment of noradrenaline infusion, the urinary excretion of the amine was highest during infusion, then decreased rapidly to pre-infusion level in two hours, whereas the excretion of its metabolites, normetadrenaline and VMA, remained at higher level for several hours after the infusion. The excretion pattern did not significantly differ in the two groups, hyperthyroid patients and normal controls.

7) The increase in the excretion of adrenaline and metadrenaline during noradrenaline infusion was greater in hyperthyroid patients than in controls.

8) A marked increase in the excretion of methoxy catecholamines and distinct decrease in urinary VMA were observed in healthy subjects recieving JB-516, a potent monoamine oxidase inhibitor.

\section{Acknowledgment}

I am indebted to Prof. Dr. T. Torikai for his continuous leadership throughout, this study.

\section{References}

1) Goetsch, E., New York State J. Med., 1918, 18, 259. Ref. from Ann. Int. Med., 1959, 51, 309.

2) Santesson, C.E., Scandinav. Arch. f. Physiol., 1919, 37, 185.

3) Rosenblum, H., Hahn, R.G. \& Levine, S.A., Arch. Int. Med., 1933, 51, 279.

4) Brewster, Jr. W. R., Isaacs, J. P., Osgood, P. F. \& King, T. L., Circulation, 1956, $13,1$.

5) Diller, W. F. \& Kilpatrik. R., Brit. Med., J., 1958, $2,823$.

6) Goldfien, A., Zileli, S., Goodman, D. \& Thorn, G.W., J. Clin. Endocl. \& Metabol., 1961, 21, 281.

7) Euler, U.S.v., Personal communication, 1961.

8) Spinks, A. \& Burn, J.H., Brit. J. Pharmacol., 1952, 7, 93.

9) Trendelenburg, U., Brit. J. Pharmacol., 1953, 8, 454

10) D' Iorio, A. \& Leduc. J., Arch. Biochem. Biophys., 1960, 87, 224.

11) Holtz, P., Stock, K., \& Westermann, E., Arch. exper. Pathol. Pharmakol., 1956, 228, 322.

12) Goldenberg, M., Pines, K.L., Baldwin, E.F., Green, D.G. \& Roh, C.E., Am. J. Med., 1948, 5, 792.

13) Yoshinaga, K., Nissin Igaku (Jap.), 1960, 47, 775.

14) Euler, U.S. v., Noradrenaline, Charles C. Thomas, Springfield. 1956

15) Yoshinaga, K., Itoh, C., Ishida, N., Sato, T. \& Wada, Y., Tohoku J. Exper. Med., $1961,84,105$. 
16) Sato, T., Nissin Igaku (Jap.), 1960, 47, 827.

17) Euler, U.S. v. \& Luft, R., Brit. J. Pharmacol., 1951, 6, 286.

18) Schneckloth, R.H., Kurland, G.S. \& Freedberg, A.S., Metabolism, 1953, 2, 546.

19) Murray, J.F. Kelly, Jr. J.J., Ann. Int. Med., 1959, 51, 309.

20) Spinks, A., J. Physiol., 1952, 117, 35P.

21) Burn, J.H., Brit. Med., J., 1952, 1, 784.

22) Burn, J.H., Lancet, 1958, 2, 1213.

23) Yoshinaga, K., Sato, T. \& Ishida, N., Tohoku J. Exper. Med., 1960, 72, 301.

24) Mowbray, J. F. \& Peart, W.S., J. Physiol., 1960, 151, 261.

25) Zile, M. \& Lardy, H.A., Arch. Biochem. \& Biophys., 1959, 82, 411.

26) Resnick, O., Wolfe, J. M., Freeman, H. \& Elmadjian, F., Science, 1958, 127, 1116.

27) Cohen, G., Holland, B., Sha, J. \& Goldenberg, M., J. Clin. Invest., 1959, 38, 1935.

28) Burn, J. H. \& Rand, M.J., Brit. Med. J.. 1959, 2, 394.

29) Axerlod, J., Experientia, 1960, 16, 502.

30) Hertting, G., Axerlod. J., Whitby, G. \& Patrick, R., Fed. Proc., 1961, 20, Part I.

31) De Schaepdryver, A.F., Arch. Int. Pharmacodyn., 1959, 121, 478.

32) Goodall, MeC., Acta Physiol. Scand., 1951, 24, suppl. 85.

33) Ledue, J., Dubrenil, R. \& D' Iorio, A., Canad. J. Biochem. \& Physiol., 1955, 33, 238. 